\title{
Sex chromosome differentiation in Belostoma (Insecta: Heteroptera: Belostomatidae)
}

\author{
V.B. Bardella ${ }^{1,2}$, A.L. Dias ${ }^{1}$, L. Giuliano-Caetano ${ }^{1}$, J.R.I. Ribeiro ${ }^{3}$ and \\ R. Da Rosa ${ }^{1}$ \\ 'Departamento de Biologia Geral, CCB, \\ Universidade Estadual de Londrina, Londrina, PR, Brasil \\ ${ }^{2}$ Instituto de Biociências, Letras e Ciências Exatas, \\ Departamento de Biologia, Universidade Estadual Paulista, \\ São José do Rio Preto, São Paulo, SP, Brasil \\ ${ }^{3}$ Universidade Federal do Pampa, Campus São Gabriel, \\ São Gabriel, RS, Brasil \\ Corresponding author: R. Da Rosa \\ E-mail: renata-darosa@uel.br
}

Genet. Mol. Res. 11 (3): 2476-2486 (2012)

Received September 19, 2011

Accepted February 8, 2012

Published May 21, 2012

DOI http://dx.doi.org/10.4238/2012.May.21.2

\begin{abstract}
Belostoma, a genus of the family Belostomatidae, includes species of great ecological importance as biocontrol agents. Few species of these species have been the subject of cytogenetic analyses. Karyotypic evolution in this genus involves agmatoploidy and simploidy; there are also different sex chromosome systems. We examined two Belostoma species (B. dilatatum and B. candidulum) collected from the Paranapanema River Basin (Brazil). Mitotic and meiotic analysis revealed $2 n\left(\delta^{\Uparrow}\right)=26+\mathrm{X}_{1} \mathrm{X}_{2} \mathrm{X}_{3} \mathrm{Y}$ for $B$. dilatatum and $2 n\left(\delta^{\lambda}\right)=14+\mathrm{XY}$ for $B$. candidulum; both karyotypes have holokinetic chromosomes. Differences in heterochromatin distribution were also observed between the species, besides variation in the localization of $\mathrm{CMA}_{3}{ }^{+} / \mathrm{DAPI}-$ blocks. The existence of different types of sex
\end{abstract}


chromosome systems in these species was confirmed based on arrangements of the chromosomes in different meiotic stages. We identified a new sex system in $B$. dilatatum, and make the first cytogenetic report on $B$. candidulum.

Key words: Holokinetic chromosomes; Heterochromatin; Simploidy; Sex chromosomes; Agmatoploidy

\section{INTRODUCTION}

The family Belostomatidae Leach, 1815, comprises the largest heteropterans, where it is a group with a worldwide distribution and a high diversity in the tropical region (Merritt and Cummins, 1996; Ribeiro, 2007). These are animals with predatory habits, and their ecological importance lies in the role they play as biocontrol agents, where aquatic arthropods, fish, and amphibians are its main prey (Cullen et al., 1969; Saha et al., 2010).

According to Ribeiro (2007), the family Belostomatidae is composed of eight genera with approximately 150 species, distributed in three subfamilies: Belostomatinae, Horvathiniinae and Lethocerinae (Lauck and Menke, 1961). The first subfamily has the highest number of genera, among which Belostoma is the most diverse (Lauck and Menke, 1961; Ribeiro, 2005). The systematics of this genus is confusing since the different species of Belostoma have a similar morphology, and also because few studies have been conducted in Brazil (Ribeiro, 2007).

Most of the chromosomal analyses in species of the family Belostomatidae have been restricted to conventional analyses (Table 1). The cytogenetic data show that most species have males with chromosome numbers ranging from $2 n=4$ in Lethocerus sp. (Chickering, 1927, 1932) to $2 n=29$ in some species of Belostoma (Papeschi and Bidau, 1985; Papeschi, 1988, 1991). Nevertheless, analyzed species showed holokinetic chromosomes, a characteristic common to all species of heteropterans (Papeschi and Bressa, 2006). Besides the wide variation in diploid number, most species have different sex chromosome systems (Table 1). Simple and multiple systems have been reported in the genus Belostoma, and in all cases the male was the heterogametic sex.

Papeschi and Bressa (2006) proposed an ancestral karyotype with $2 n=26+\mathrm{XY}$ for the genus, substantiating that in the genus Belostoma, chromosomal evolution supposedly occurred by simploidy (fusion) and agmatoploidy (fission), as happens in many organisms with holokinetic chromosomes. Simploidy events would be related to a decrease in the diploid number without changes in the type of sex chromosome system. The formation of a multiple sex chromosome would be attributed to agmatoploidy, by which the $\mathrm{X}$ chromosome would undergo fragmentations resulting in two new $\mathrm{X}$ chromosomes $\left(\mathrm{X}_{1} \mathrm{X}_{2}\right)$.

Although there is evidence of the mode of karyotypic evolution in the genus Belostoma, much about these events still remains unknown. In order to provide a more detailed characterization of chromosomal diversity and a better understanding of the karyotypic evolution in this group, we investigated two species of Belostoma through chromosomal markers. The cytogenetic data for one of the species are previously unpublished, and so are data on the occurrence of a new sex chromosome system in the other. The mechanisms involved in the evolution of these systems are also discussed. 


\begin{tabular}{|c|c|c|c|}
\hline Subfamily & Species & Diploid number $(2 n)$ & References \\
\hline \multirow[t]{27}{*}{ Belostomatinae } & \multirow[t]{2}{*}{ Belostoma elegans } & $29\left(26+X_{1} X_{2} Y^{\Uparrow}\right)$ & Papeschi (1988), Papeschi (1991) \\
\hline & & $29 / 30\left(26+X_{1} X_{2} Y^{\prime} / X_{1} X_{1} X_{2} X_{2}\right.$ ㅇ $)$ & Papeschi and Bidau (1985) \\
\hline & B. bergi & $29\left(26+X_{1} X_{2} Y^{3}\right)$ & $\begin{array}{l}\text { Papeschi and Bressa (2004) apud } \\
\text { Papeschi and Bressa (2006) }\end{array}$ \\
\hline & B. bifoveolatum & $29\left(26+\mathrm{X}_{1} \mathrm{X}_{2} \mathrm{Y}^{\lambda}\right)$ & Papeschi (1991) \\
\hline & B. cummingsi & $29 / 30\left(26+X_{1}^{2} X_{2} Y^{\prime} / X_{1} X_{1} X_{2} X_{2}\right.$ ㅇ $)$ & Papeschi and Bidau (1985) \\
\hline & B. dentatum & $29\left(26+X_{1} X_{2} Y^{7}\right)$ & Papeschi and Bidau (1985), Papeschi (1991) \\
\hline & \multirow[t]{2}{*}{ B. dilatatum } & $29\left(26+X_{1}^{1} X_{2}^{2} Y_{0}\right)$ & Papeschi (1992) \\
\hline & & $30\left(26+X_{1} X_{2}^{2} X_{3} Y^{1}\right)$ & Present study \\
\hline & B. discretum & $29\left(26+X_{1}^{1} X_{2}^{2} Y_{0}^{3}\right)$ & $\begin{array}{l}\text { Papeschi and Bressa (2004) apud } \\
\text { Papeschi and Bressa (2006) }\end{array}$ \\
\hline & B. elongatum & $29\left(26+X_{1} X_{2} Y^{\Uparrow}\right)$ & Papeschi (1992) \\
\hline & B. gestroi & $29\left(26+X_{1} X_{2}^{2} Y^{\lambda}\right)$ & Papeschi (1992) \\
\hline & B. martini & $29\left(26+X_{1} X_{2}^{2} Y{ }^{7}\right)$ & Papeschi (1991) \\
\hline & B. indentatum & $29\left(26+\mathrm{X}_{1} \mathrm{X}_{2} \mathrm{Y}^{\lambda}\right)$ & Ueshima (1979) \\
\hline & \multirow[t]{3}{*}{ B. plebejum } & $16\left(14+X Y_{0}^{2}\right)$ & \multirow[t]{3}{*}{ Papeschi (1994) } \\
\hline & & $15(13+\mathrm{XY} \precsim)$ & \\
\hline & & $17\left(14+\mathrm{X}_{1} \mathrm{X}_{2} \mathrm{Y}^{\Uparrow}\right)$ & \\
\hline & \multirow[t]{2}{*}{ Belostoma $\mathrm{sp}$} & $16\left(14+\mathrm{XY}^{\hat{\jmath}}\right)$ & \multirow[t]{2}{*}{ Papeschi (1996) } \\
\hline & & $17\left(14+\mathrm{X}_{1} \mathrm{X}_{2} \mathrm{Y}^{\Uparrow}\right)$ & \\
\hline & B. flumineum & $24(22+X Y)$ & $\begin{array}{l}\text { Chickering (1916, 1927b) apud } \\
\text { Papeschi (1988) }\end{array}$ \\
\hline & Belostoma sp & $24(22+X Y \precsim)$ & $\begin{array}{l}\text { Montgomery (1901, 1906) apud } \\
\text { Papeschi (1988) }\end{array}$ \\
\hline & B. candidulum & $16(14+\mathrm{XY} \precsim)$ & Present study \\
\hline & B. micantulum & $16\left(14+X Y^{2}\right)$ & Papeschi (1988) \\
\hline & B. orbiculatum & $16\left(14+\mathrm{XY}^{\Uparrow}\right)$ & Papeschi (1996) \\
\hline & B. oxyurum & $8(6+X Y \precsim)$ & Papeschi (1988), Papeschi and Bidau (1985) \\
\hline & Diplonuchus annulatus & $28(26+\mathrm{XY} \hat{\jmath})$ & Jande (1959) apud Papeschi (1988) \\
\hline & D. rusticus & $28\left(26+X Y^{\pi}\right)$ & $\begin{array}{l}\text { Bawa (1953), Jande (1959) apud } \\
\text { Papeschi (1988) }\end{array}$ \\
\hline & D. subrhombeus & $28(26+\mathrm{XY} \hat{\jmath})$ & Jande (1959) apud Papeschi (1988) \\
\hline \multirow[t]{8}{*}{ Lethocerinae } & L. uhleri & 30 & $\begin{array}{l}\text { Chickering and Bacorn (1933) apud } \\
\text { Papeschi (1988) }\end{array}$ \\
\hline & L. annulipes & $28(26+\mathrm{XY})$ & Papeschi (1992) \\
\hline & Lethocerus sp1 & 28 & Chichering (1932) apud Papeschi (1988) \\
\hline & L. griseus & $28(26+X Y \precsim)$ & Chichering (1927a) apud Papeschi (1988) \\
\hline & L. melloleitaoi & $28\left(26+X Y{ }^{\pi}\right)$ & $\begin{array}{l}\text { Papeschi and Bressa (2004) apud } \\
\text { Papeschi and Bressa (2006) }\end{array}$ \\
\hline & L. indicum & $26(24+$ neo-X-neo-Yð $)$ & $\begin{array}{l}\text { Banerjee (1958), Bagga (1959), Jande (1959) } \\
\text { apud Papeschi (1988) }\end{array}$ \\
\hline & Lethocerus americamus & $8\left(6+X Y_{\bigcirc}^{\Uparrow}\right)$ & $\begin{array}{l}\text { Chickering (1927a,b) Chickering and Bacom (1933) } \\
\text { apud Papeschi (1988) }\end{array}$ \\
\hline & Lethocerus sp2 & $4(2+$ neo-X-neoY $\gtrsim)$ & Chichering (1927a) apud Papeschi (1988) \\
\hline
\end{tabular}

Adapted from Papeschi and Bressa (2006).

\section{MATERIAL AND METHODS}

\section{Samples and collection sites}

Two species of the genus Belostoma [B. dilatatum (Dufour, 1863) (10 males) and B. candidulum Montandon, 1903 (15 males)] were collected from Água do Macuco Stream, Lower Paranapanema River basin (22 $54^{\prime} 15.3^{\prime \prime} \mathrm{S}$ and $\left.50^{\circ} 23^{\prime} 47.98^{\prime \prime} \mathrm{W}\right)$, between the states of Paraná and São Paulo, Brazil. Individuals from each species were deposited at Universidade Federal do Pampa (UNIPAMPA). 


\section{Chromosome preparations and conventional staining}

The gonads of the adult specimens were dissected in physiological solution for insects (7.5 g NaCl, $2.38 \mathrm{~g} \mathrm{Na}_{2} \mathrm{HPO}_{4}$ and $2.72 \mathrm{~g} \mathrm{KH}_{2} \mathrm{PO}_{4}$ in $1 \mathrm{~L}$ distilled water). The testicles were treated with a hypotonic solution (tap water) for 3 min and fixed in Carnoy I ( $3: 1$, methanol:acetic acid) for $30 \mathrm{~min}$. Chromosome preparations were made by cellular suspension by maceration in one drop of $45 \%$ acetic acid, with each gonad previously treated with $45 \%$ acetic acid. These preparations were submitted to conventional staining with $3 \%$ Giemsa and also to chromosome banding techniques.

\section{Chromosome banding}

Silver nitrate staining of active nucleolar organizer regions (Ag-NOR) was performed according to Howell and Black (1980). The distribution of heterochromatin was analyzed by Giemsa C-banding after treatments with $0.2 \mathrm{M} \mathrm{HCl}, \mathrm{Ba}(\mathrm{OH})_{2}$ and 2X SSC (Sumner, 1972). The GC- and AT-rich bands were detected with chromomycin $\mathrm{A}_{3}\left(\mathrm{CMA}_{3}\right)$ and 4'-6-diamino2-phenylindole (DAPI), respectively, according to Schweizer (1976). The slides were stained with $0.5 \mathrm{mg} / \mathrm{mL} \mathrm{CMA}_{3}$ for $1.5 \mathrm{~h}$, washed in distilled water and sequentially stained with $2 \mu \mathrm{g} /$ $\mathrm{mL}$ DAPI for $30 \mathrm{~min}$. Slides were mounted with a medium composed of glycerol/Mcllvaine buffer, $\mathrm{pH}$ 7.0, 1:1, plus $2.5 \mathrm{mM} \mathrm{MgCl}$.

\section{RESULTS}

\section{B. dilatatum}

The chromosomal number observed in all samples of $B$. dilatatum was $2 n\left(\circlearrowleft^{\lambda}\right)=30=$ $26+\mathrm{X}_{1} \mathrm{X}_{2} \mathrm{X}_{3} \mathrm{Y}$ (Figure 1). By conventional analysis, large interphasic nuclei with several welldefined chromocenters were observed (Figure 1a). In pachytene, the homologues were associated, and curved filament-like structures were observed, where it was difficult to distinguish the bivalents (Figure $1 \mathrm{~b}$ and $\mathrm{c}$ ). Heterochromatic blocks were located terminally on all bivalents, and interstitial dots were also observed. Sex chromosomes were positively heteropycnotic and usually associated with each other (Figure 1b and c). During diplotene/diakinesis, 1 or 2 chiasmata per bivalent were observed, while the separate sex chromosomes remained univalent (Figure 1d).

The results of the analyses of meiocytes in metaphases I and II confirmed that bivalents divide reductionally, and sex chromosomes, equationally (Figure 1e and f). In metaphase II, the bivalents were arranged in a ring and the univalent sex chromosomes were positioned inside the ring as a pseudo-tetravalent. This was confirmed by the fact that during that period, 17 structures corresponding to 13 autosomal and four sex chromosomes were observed. The $Y$ chromosome probably corresponded to the large structure evidenced in the pseudo-tetravalent, while the other three smaller chromosomes corresponded to the $X_{1}, X_{2}$ and $X_{3}$ (Figure 1f).

Staining with fluorochromes showed chromocenters $\mathrm{CMA}_{3}^{+} / \mathrm{DAPI}^{+}$(Figure $2 \mathrm{a}$ and f); however, in interphasic nucleus, two $\mathrm{CMA}_{3}^{+} / \mathrm{DAPI}$ regions were observed (Figure 2). In pachytene, heterochromatic blocks were observed, confirming the $\mathrm{CMA}_{3}^{+} / \mathrm{DAPI}^{+}$characteristic of the heterochromatin (Figure $2 \mathrm{~b}$ and $\mathrm{g}$ ). $\mathrm{A} \mathrm{CMA}_{3}^{+} / \mathrm{DAPI}-$ block was observed in one of the 
bivalents, probably corresponding to the staining evidenced in the interphasic nucleus (Figure 21). This block impregnated by silver nitrate, confirmed the existence of Ag-NORs (Figure 1g).
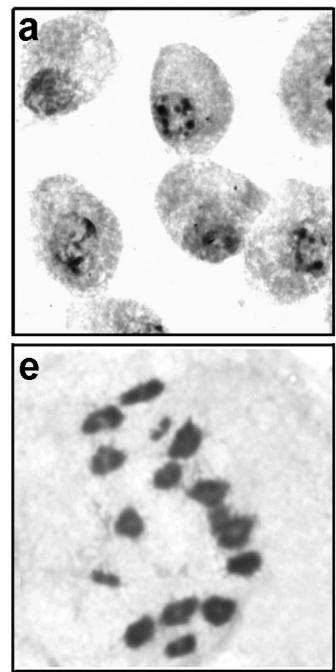

i
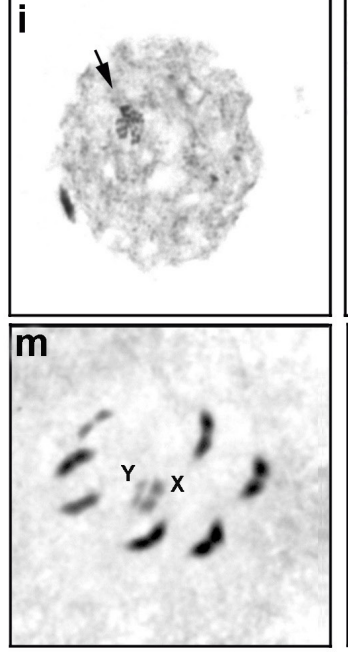
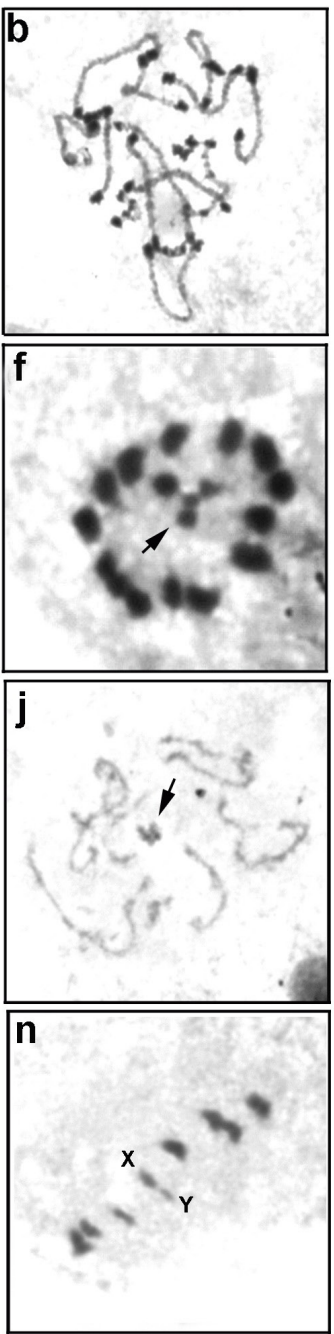
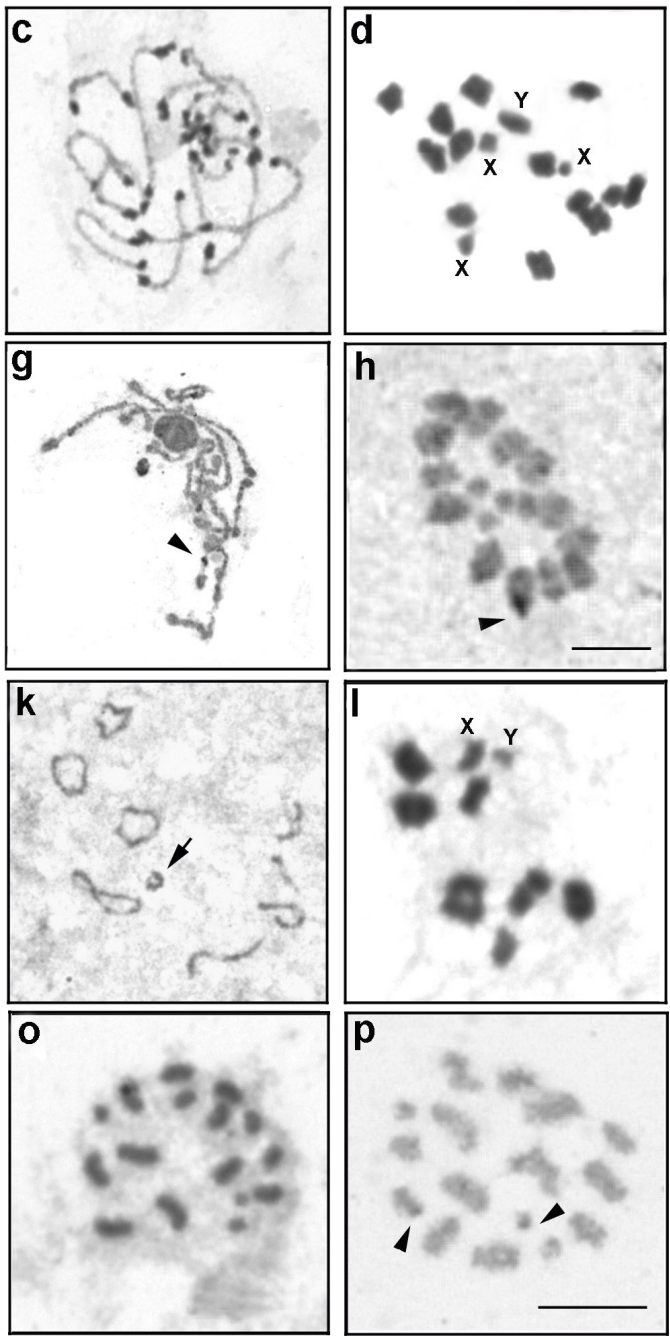

Figure 1. Meiotic stages in Belostoma dilatatum (a-h) and B. candidulum (i-p): a. Interphasic nucleus; note the quantity and distribution of chromocenters. b and c. Pachytene; note the distribution of heterochromatic blocks. $\mathbf{d}$. Diplotene/diakinesis; sex chromosomes are viewed as univalents. e. Transition between diakinesis and metaphase I. f. Metaphase II; arrows show the sex chromosomes inside the ring formed by autosomes. $\mathbf{g}$ and $\mathbf{h}$. Pachytene and metaphase II staining by silver nitrate, respectively; arrowheads show Ag-NOR. i. Interphasic nucleus; arrows show the chromocenter corresponding to NOR. j. Pachytene; arrow indicates the association between sex chromosomes. k. Diplotene; note the chiasmata; arrow indicates associated sex chromosome. l. Diakinesis; note sex chromosomelike univalents. m. Metaphase I; sex chromosome inside ring autosomes. n. Metaphase II; note the touch-andgo pairing between $\mathrm{X}$ and Y. o and p. Mitotic metaphase in conventional staining and Ag-NOR, respectively; arrowheads show the NOR-bearing chromosomes. Bars $=10 \mu \mathrm{m}$. 

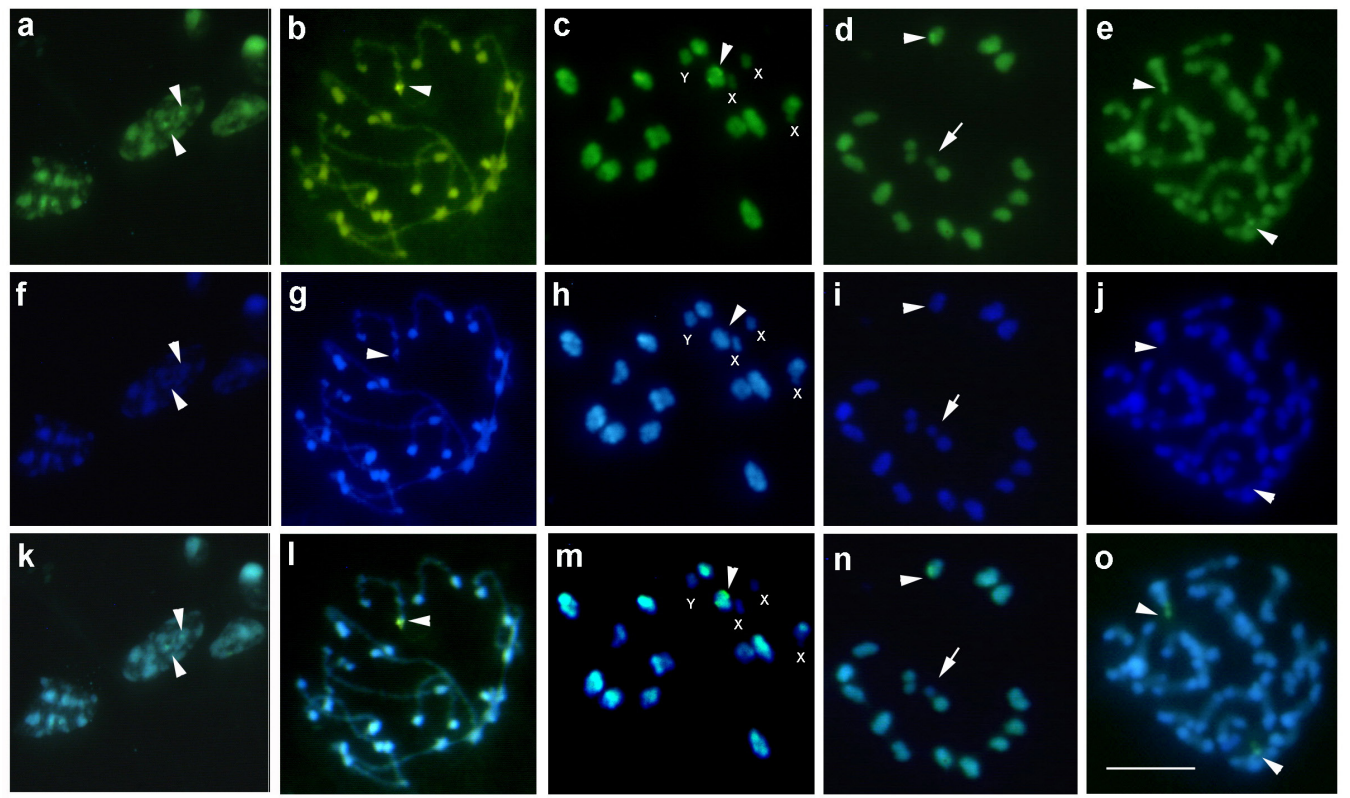

Figure 2. Fluorochrome staining in Belostoma dilatatum: $(\mathbf{a}-\mathbf{e}) \mathrm{CMA}_{3} ;(\mathbf{f}-\mathbf{j})$ DAPI; $(\mathbf{k}-\mathbf{o})$ overlapping $\mathrm{CMA}_{3} / \mathrm{DAPI}$. a. f. k. Interphasic nucleus. b. g. l. Pachytene. c. h. m. Diakinesis; note the distribution of heterochromatic blocks. d. i. n. Metaphase II. e. j. o. Mitotic metaphase. Arrows show the sex chromosomes. Arrowheads indicate $\mathrm{CMA}_{3}^{+} /$ DAPI- sites; note the presence of these sites in autosomes. Bars $=10 \mu \mathrm{m}$.

In diakinesis, the presence of heterochromatic blocks in autosomes was confirmed (Figure $2 \mathrm{c}, \mathrm{h}$ and $\mathrm{m}$ ). In metaphase II, sex chromosomes showed no highlighted blocks, while one of the autosomes displayed a $\mathrm{CMA}_{3}^{+}$/DAPI- block (Figure 2d, i and n) and also Ag-NORs (Figure 1h).

The analysis of spermatogonial cells in mitotic metaphase showed the terminal and interstitial distribution of heterochromatic blocks, and the occurrence of a $\mathrm{CMA}_{3}^{+} / \mathrm{DAPI}^{-}$block in the terminal region of a medium-sized chromosomal pair (Figure $2 \mathrm{e}, \mathrm{j}$ and o).

\section{B. candidulum}

All B. candidulum samples showed $2 n\left({ }^{\Uparrow}\right)=16=14+\mathrm{XY}$, with the karyotype composed of 1 small, 9 medium, and 4 large chromosomes, all holokinetic (Figure 1p). The X chromosome was characterized as medium-sized chromosome, and the $\mathrm{Y}$, as small-sized chromosome (Figure $1 \mathrm{~m}$ and $\mathrm{n}$ ). In the analysis of the nuclei, only one chromocenter and one region with positive heteropycnosis were observed (Figure 1i).

Pachytene showed the association of bivalents, which, in addition, showed little heterochromatin located in the region of association among sex chromosomes (Figure $1 \mathrm{j}$ and $\mathrm{k}$ ). In diplotene, 1 or 2 chiasmata per bivalent were observed, and the sex chromosomes were associated (Figure 1k). In diakinesis, the sex chromosomes were dissociated and became univalent (Figure 11). In metaphase I, bivalents were arranged in a ring in the periphery, while the sex chromosomes were positioned inside in lateral conformation (Figure 1m). In metaphase II, X and Y 
chromosomes displayed negative heteropycnosis and in touch-and-go conformation (Figure 1n).

After C-banding and $\mathrm{CMA}_{3} / \mathrm{DAPI}$ staining, the $\mathrm{CMA}_{3}^{+} / \mathrm{DAPI}{ }^{-}$blocks were localized. $\mathrm{CMA}_{3}^{+} / \mathrm{DAPI}^{-}$blocks were observed in the chromocenter (Figure 3a, e and i), and these blocks were also observed in pachytene (Figure $3 \mathrm{~b}, \mathrm{f}$ and $\mathrm{j}$ ). In diplotene, these blocks were distributed in the sex chromosomes (Figure $3 \mathrm{c}, \mathrm{g}$ and $\mathrm{k}$ ), where $\mathrm{X}$ showed one block in the terminal region and $\mathrm{Y}$ showed staining in both terminations (Figure 3 box). In the mitotic metaphases, $\mathrm{CMA}_{3}{ }^{+}$DAPI blocks (Figure 3d, h and 1), which were coincident with Ag-NORs, could also be seen (Figure 1p). Thus, we demonstrated the presence of these sequences on the sex chromosomes and their total absence on the autosomes.
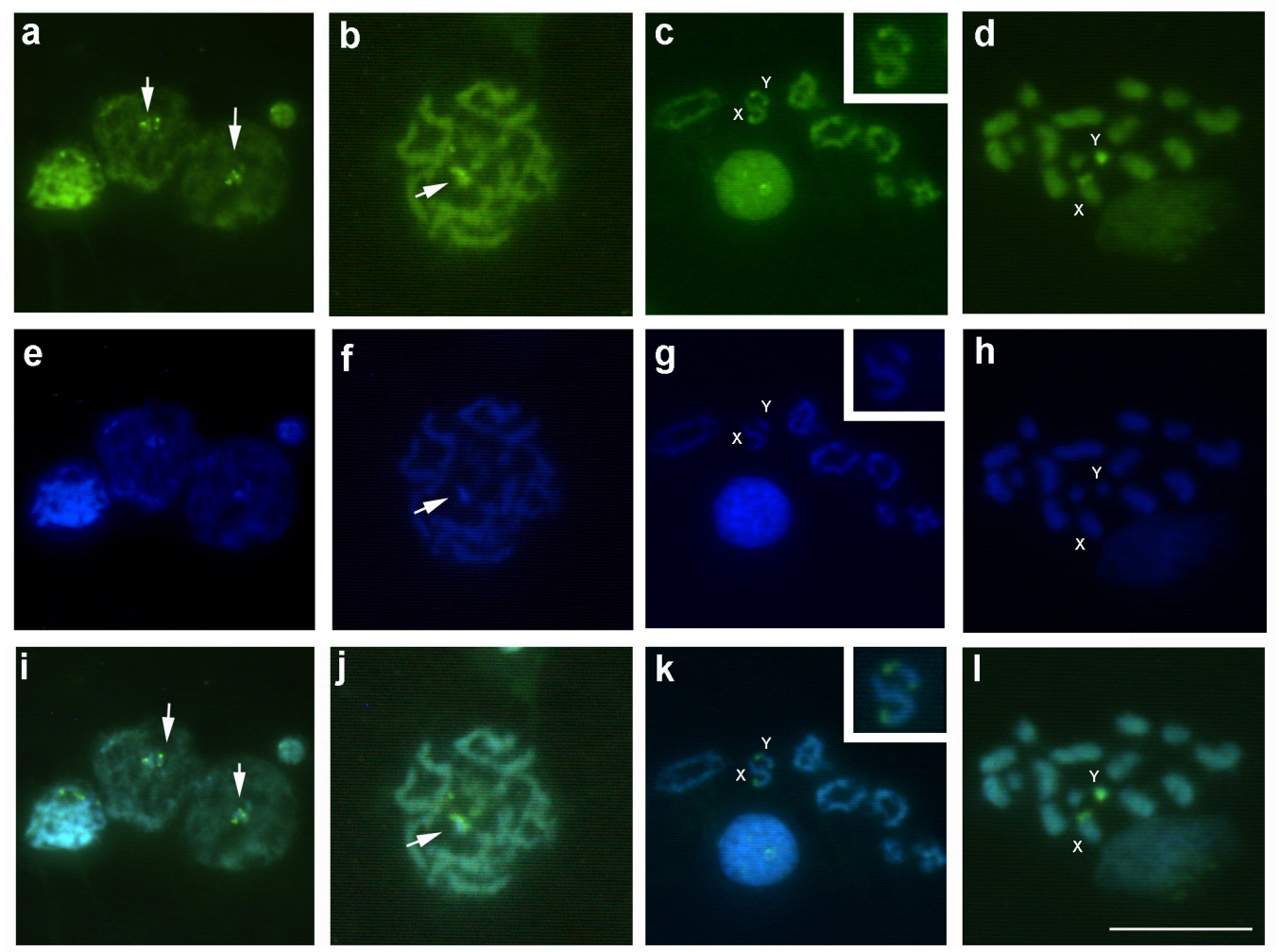

Figure 3. Fluorochrome staining in Belostoma candidulum: (a-d) $\mathrm{CMA}_{3}$; (e-h) DAPI; (i-l) overlapping $\mathrm{CMA}_{3} /$ DAPI. a. e. i. Interphasic nucleus. b. f. j. Pachytene. c. g. k. Diplotene; box: association between $\mathrm{X}$ and $\mathrm{Y}$ chromosomes. d. h. l. Mitotic metaphase. Arrows indicate $\mathrm{CMA}_{3}^{+} / \mathrm{DAPI}$ sites; note the presence of these sites in sex chromosomes. Bars $=10 \mu \mathrm{m}$.

\section{DISCUSSION}

Conventional analysis of the two species of Belostoma revealed $2 n(\widehat{\delta})=30=26+$ $\mathrm{X}_{1} \mathrm{X}_{2} \mathrm{X}_{3} \mathrm{Y}$ for $B$. dilatatum and $2 n\left(\delta^{\Uparrow}\right)=16=14+\mathrm{XY}$ for $B$. candidulum. Similar karyotypes were reported by different authors for other species of the genus (Table 1). In addition to defin- 
ing the diploid number, conventional mitotic and meiotic analysis confirmed the occurrence of holokinetic chromosomes in the species studied, a common feature of all heteropterans (Jacobs, 2004; Papeschi and Bressa, 2006; Bardella et al., 2010).

The arrangement of univalent sex chromosomes in a pseudo-tetravalent, with autosomes forming a ring in the periphery during metaphase II, confirmed the existence of three $\mathrm{X}$ and one $\mathrm{Y}$ chromosomes, where the $\mathrm{Y}$ corresponds to the largest, and the $\mathrm{X}$ to smaller chromosomes arranged in a semicircle around the $\mathrm{Y}$ (Figure 1f). Fragmentation of the $\mathrm{X}$ chromosome is recurrent in this genus, and this arrangement has already been described for other species of Belostoma with a multiple sex chromosome system, such as B. elegans Mayr, 1871, B. cummingsi De Carlo, 1930, and B. dentatum Nieser, 1975 (Papeschi and Bidau, 1985).

A great variation in the diploid number is observed in the genus, with $2 n=8(6+\mathrm{XY})$ to $2 n=29\left(26+\mathrm{X}_{1} \mathrm{X}_{2} \mathrm{Y}\right)$, the latter being the most common (table 1$)$. All males of $B$. dilatatum analyzed in this work showed 30 chromosomes, suggesting $2 n=32\left(26+X_{1} X_{1} X_{2} X_{2} X_{3} X_{3}\right)$ for the females, considering that this diploid number is probably fixed in the population. Thus far, $B$. dilatatum is the species with the highest number of chromosomes in the genus. This variation in chromosome number occurs because holokinetic chromosomes that undergo a breakdown (agmatoploidy) or fusion (simploidy) (Luceño and Guerra, 1997) remain viable in subsequent cell divisions. This was demonstrated in experiments with X- and $\gamma$-rays in Rhynchospora pubera (Vahl) Boeck (Vanzela and Colaço, 2002).

The cytogenetic data available for the family Belostomatidae so far have led to the proposal of an ancestral karyotype $2 n=26+\mathrm{XY}$ (Papeschi and Bressa, 2006). Data on this ancestral karyotype suggest that agmatoploidy events have originated the common karyotype found in the genus Belostoma $\left(2 n=26+\mathrm{X}_{1} \mathrm{X}_{2} \mathrm{Y}\right)$. A second agmatoploidy event has probably occurred in the sex chromosomes of $B$. dilatatum samples analyzed in this work, resulting in the karyotype $2 n=$ $26+\mathrm{X}_{1} \mathrm{X}_{2} \mathrm{X}_{3} \mathrm{Y}$ (Figure 4). Sex chromosome systems with multiple $\mathrm{X}$ chromosomes are common in Heteroptera, but the occurrence of $\mathrm{X}_{1} \mathrm{X}_{2} \mathrm{X}_{3} \mathrm{Y}$ was observed in the Belostomatidae for the first time. Other reports of this system were described in a few species of Pentatomidae, Aradidae, and Reduviidae (Heizer, 1950; Jacobs, 1986; Severi-Aguiar et al. 2006).

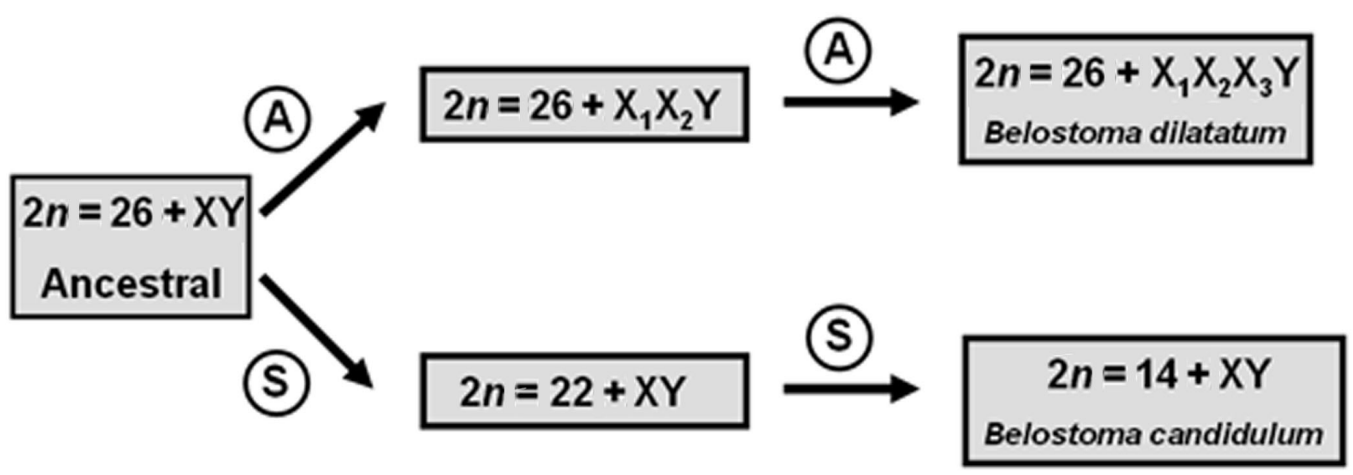

Figure 4. Scheme suggesting the karyotype differentiation and evolution in Belostoma dilatatum and B. candidulum. $2 n=26+\mathrm{XY}$ : ancestral karyotype suggested by Papeschi and Bressa (2006). A = Agmatoploidy. The first event involved the $\mathrm{X}$ chromosome resulting in the multiple system of sex chromosomes; the second event of agmatoploidy probably occurred giving rise to the multiple system $\mathrm{X}_{1} \mathrm{X}_{2} \mathrm{X}_{3} \mathrm{Y}$ of $B$. dilatatum. $\mathrm{S}=$ Simploidy. Simploidy seems to have occurred between the autosomal chromosomes in the ancestral karyotype; other simploidy events possibly occurred between autosomes, and also autosomes and sex chromosomes, resulting in the karyotype found in B. candidulum. 
Papeschi (1996), in analyzing different populations of Belostoma sp, found an interspecific polymorphism of sex chromosomes, where two karyotypes could be observed: 1) $2 n$ $=16=14+\mathrm{XY}$, in most males; and 2) $2 n=17=14+\mathrm{X}_{1} \mathrm{X}_{2} \mathrm{Y}$. The author attributed the origin of the multiple sex system to the fragmentation of the $\mathrm{X}$ chromosome of the first karyotype. Furthermore, the samples with $2 n=17$ showed meiotic instability with three different arrangements in metaphase II. Therefore, the Belostoma sp samples represented direct evidence of the mechanism of the origin of sex chromosomes by agmatoploidy, which probably also occurred in $B$. dilatatum samples, the subject of this study.

While agmatoploidy is probably the most important event in karyotypic evolution in $B$. dilatatum, simploidy seems to be a major chromosomal rearrangement in B. candidulum, as well as in other species of Belostoma with reduced diploid numbers (Figure 4 and Table 1).

B. candidulum showed $2 n\left(\delta^{\Uparrow}\right)=16=14+\mathrm{XY}$ and a karyotype composed of holokinetic chromosomes. The $\mathrm{X}$ chromosome corresponds to a medium-sized chromosome, and the $\mathrm{Y}$, to small-sized chromosome. This karyotypic organization has been observed in other species of the genus, such as B. micantulum (Stål, 1860) (Papeschi, 1988), B. plebejum (Stål, 1860) (Papeschi, 1994), and B. orbiculatum Estévez and Polhemus, 2001 (Papeschi, 1996).

During the meiotic divisions, it was possible to observe the association between the sex chromosomes of $B$. candidulum, mainly in prophase I (pachytene and diplotene). This association is probably related to the fact that these chromosomes are bearers of nucleolus organizer regions. This was evident by impregnation with silver nitrate and staining with fluorochromes. The interphasic nucleus showed a nucleolus with $\mathrm{CMA}^{+} / \mathrm{DAPI}-$ blocks, and during the other phases, sex chromosomes with Ag-NORs and $\mathrm{CMA3}^{+} / \mathrm{DAPI}{ }^{-}$were observed. In diplotene, the association between these chromosomes and the location of $\mathrm{CMA}^{+} / \mathrm{DAPI}^{-}$blocks was observed (Figure 3 box).

Ueshima (1979) proposed that the sex chromosome system XX/XY is ancestral in the suborder Heteroptera. If we consider this proposal, together with the ancestral karyotype of Belostoma $(2 n=26+\mathrm{XY})$ (Papeschi and Bressa, 2006), we can propose that there was no agmatoploidy in the origin of sex chromosomes in B. candidulum. However, a reduction in the diploid number leads us to infer the occurrence of various simploidy events in the species (Figure 4), as proposed by Papeschi and Bressa (2006) for other species of the genus with a reduced diploid number.

Evidence is supported by the occurrence of simploidy in karyotypic evolution of Belostoma. Analyses by fluorescent in situ hybridization with $18 \mathrm{~S}$ rDNA probes in three species of the genus showed the presence of rDNA sites, which correspond to $\mathrm{CMA}^{+} / \mathrm{DAPI}{ }^{-}$blocks (Papeschi and Bressa, 2006) on autosomes of B. elegans $\left(2 n=26+\mathrm{X}_{1} \mathrm{X}_{2} \mathrm{Y}\right)$ and on sex chromosomes of $B$. oxyurum Lauck, $1962(2 n=6+\mathrm{XY})$ and B. micantulum $(2 n=14+\mathrm{XY})$. The authors proposed that the reduction in the diploid number probably involved the fusion of an ancestral pair of sex chromosomes with a NOR-bearing autosomal pair, and that there was a loss of heterochromatin during the fusions.

For B. candidulum, evidence is supported by the presence of Ag-NOR and $\mathrm{CMA3}^{+} /$ DAPI- blocks in sex chromosomes, unlike what occurred in $B$. dilatatum, where these stainings were observed in autosomes.

The simploidy between sex chromosomes and autosomes is also evidenced in other heteropteran species. In Dysdercus albofasciatus Berg 1878, cytogenetic analyses by different techniques revealed the occurrence of a neo-X and neo-Y sex chromosome system, which 
would have evolved by the insertion of an ancestral $X$ chromosome in an autosome, and as a result, the autosome homologue became the neo-Y chromosome (Bressa et al., 2009).

These events probably also occurred in the samples of the genus Belostoma studied here. A wide difference in the distribution of heterochromatic blocks could be observed between the species analyzed. While $B$. dilatatum showed a large number of heterochromatic blocks distributed in the terminal regions of the chromosomes, $B$. candidulum showed little heterochromatin, which was restricted to the sex chromosomes. This supported the hypothesis of Papeschi and Bressa (2006) that species with a low diploid number have reduced heterochromatin. Furthermore, the distribution of Ag-NOR and $\mathrm{CMA3}^{+} / \mathrm{DAPI}-$ blocks allows us to infer that $B$. dilatatum had a karyotype evolution driven mainly by the agmatoploidy of sex chromosomes, while the karyotype of $B$. candidulum evolved by simploidy between autosomes and sex chromosomes.

\section{ACKNOWLEDGMENTS}

Research supported by the Brazilian agencies CNPq (Conselho Nacional de Desenvolvimento Científico e Tecnológico), Fundação Araucária and Universidade Estadual de Londrina. We are grateful to Paulo Roberto Maximiano da Silva for his help in field work, and to IBAMA (Instituto Brasileiro do Meio Ambiente e dos Recursos Naturais Renováveis) for permission to carry out the collections and field work.

\section{REFERENCES}

Bardella V, Gaeta M, Vanzela A and Azeredo-Oliveira M (2010). Chromosomal location of heterochromatin and 45S rDNA sites in four South American triatomines (Heteroptera: Reduviidae). Comp. Cytogenet. 4: 141-149.

Bressa MJ, Papeschi AG, Vitkova M, Kubickova S, et al. (2009). Sex chromosome evolution in cotton stainers of the genus Dysdercus (Heteroptera: Pyrrhocoridae). Cytogenet. Genome Res. 125: 292-305.

Chickering AM (1927). An unusual complex in Lethocerus. Anat. Rec. 37: 156.

Chickering AM (1932). Spermatogenesis in the Belostomatidae. III. The chromosomes in the male germ cells of a Lethocerus from New Orleans, Louisiana. Pap. Mich. Acad. Sci. 15: 357-360.

Cullen MJ (1969). The biology of giant water bugs (Hemiptera : Belostomatidae) in Trinidad. Proc. R Entomol. Soc. Lond. 44: 123-136.

Heizer P (1950). The mode of bivalent orientation in the Hemiptera. Hereditas 38: 420-434.

Howell WM and Black DA (1980). Controlled silver-staining of nucleolus organizer regions with a protective colloidal developer: a 1-step method. Experientia 36: 1014-1015.

Jacobs DH (1986). Morphology and taxonomy of sub-Saharan Aneurus species with notes on their phylogeny, biology and cytogenetics (Heteroptera: Aradidae: Aneurinae). Entomol. Mem. Dep. Agric. Wat. Supply Repub. S Afr. 64: 1-45.

Jacobs DH (2004). The evolution of a neo-XY1Y2 sex chromosome system by autosome-sex chromosome fusion in Dundocoris nodulicarinus Jacobs (Heteroptera: Aradidae: Carventinae). Chrom. Res. 12: 175-191.

Lauck DR and Menke AS (1961). The higher classification of the Belostomatidae (Hemiptera). Ann. Entomol. Soc. Am. 54: 644-657.

Luceño M and Guerra M (1997). Numerical variation in species exhibiting holocentric chromosomes: a nomenclatural proposal. Caryologia 49: 301-309.

Merritt RW and Cummins KW (1996). An Introduction to the Aquatic Insects of North America. Kendal/Hunt Publishing Company, Dubuque.

Papeschi AG (1988). C-banding and DNA content in three species of Belostoma (Heteroptera) with large differences in chromosome size and number. Genetica 76: 43-51.

Papeschi AG (1991). DNA content and heterochromatin variation in species of Belostoma (Heteroptera, Belostomatidae). Hereditas 115: 109-114.

Papeschi AG (1994). Chromosome rearrangements in Belostoma plebejum (Stål) (Belostomatidae, Heteroptera). Caryologia 47: 223-231. 
Papeschi AG (1996). Sex chromosome polymorphism in a species of Belostoma (Belostomatidae, Heteroptera). Hereditas 124: $269-274$.

Papeschi AG and Bidau CJ (1985). Chromosome complement and male meiosis in four species of Belostoma Latreille (Heteroptera-Belostomatidae). Rev. Bras. Genet. 8: 249-261.

Papeschi AG and Bressa MJ (2006). Evolutionary cytogenetics in Heteroptera. J. Biol. Res. 5: 3-21.

Ribeiro JRI (2005). Família Belostomatidae Leach, 1815 (Insecta: Hemiptera: Heteroptera): Chave e Catálogo de Identificação para as Espécies Ocorrentes no Estado do Rio de Janeiro, Brasil. Arquivos do Museu Nacional, Rio de Janeiro, 247-262.

Ribeiro JRI (2007). A review of the species of Belostoma Latreille, 1807 (Hemiptera: Heteroptera: Belostomatidae) from the four southeastern Brazilian states. Zootaxa 1477: 1-70.

Saha N, Aditya G, Saha GK and Hampton S (2010). Opportunistic foraging by heteropteran mosquito predators. Aquat. Ecol. 44: 167-176.

Schweizer D (1976). Reverse fluorescent chromosome banding with chromomycin and DAPI. Chromosoma 58: 307-324.

Severi-Aguiar GD, Lourenco LB, Bicudo HE and Azeredo-Oliveira MT (2006). Meiosis aspects and nucleolar activity in Triatoma vitticeps (Triatominae, Heteroptera). Genetica 126: 141-151.

Sumner AT (1972). A simple technique for demonstrating centromeric heterochromatin. Exp. Cell Res. 75: 304-306.

Ueshima N (1979). Hemiptera II: Heteroptera. In: Animal Cytogenetics. v3: Insecta 6 (John B, ed.). Gebrüder Borntraeger, Berlin, 117.

Vanzela ALL and Colaço W (2002). Mitotic and meiotic behavior of y irradiated holocentric chromosomes of Rhynchospora pubera (Cyperaceae). Acta Scient. 24: 611-614. 